\title{
Role of Mixed Lineage Kinase Inhibition in Neonatal Hypoxia-Ischemia
}

\author{
Ylva Carlsson ${ }^{a, b}$ Anna-Lena Leverin ${ }^{b}$ Maj Hedtjärn ${ }^{b, c}$ Xiaoyang Wang ${ }^{b}$ \\ Carina Mallard $^{b}$ Henrik Hagberg ${ }^{a, b}, d$ \\ Departments of a Obstetrics and Gynecology, and ${ }^{b}$ Neuroscience and Physiology, Perinatal Center, Sahlgrenska \\ Academy, Gothenburg University, Gothenburg, Sweden; ' Santaris Pharma A/S, Hørsholm, Denmark; ' Institute of \\ Reproductive and Developmental Biology, Imperial College, Queen Charlotte's and Chelsea Hospital, London, UK
}

\section{Key Words}

Mixed lineage kinase inhibition $\cdot$ Neonatal

hypoxia-ischemia $\cdot$ Brain injury $\cdot$ Apoptosis $\cdot$ Inflammation

\begin{abstract}
Hypoxic-ischemic brain injury is often delayed and involves both apoptotic and immunoregulatory mechanisms. In this study, we used a neonatal model of hypoxia-ischemia to examine the effect of the mixed lineage kinase (MLK) inhibitor CEP-1347 on brain damage, apoptosis and inflammation. The tissue volume loss was reduced by $28 \%(p=0.019)$ in CEP-1347-treated versus vehicle-treated rats and CEP-1347 significantly attenuated microgliosis at 7 days $(p=0.038)$. CEP-1347 decreased TUNEL-positive staining as well as cleaved caspase 3 immunoreactivity. CEP-1347 did not affect the expression of pro-inflammatory cytokines IL-1 $\beta$, IL- 6 and MCP-1, nor did it affect the expression of OX-42 (CR3) and OX-18 (MHC I) $24 \mathrm{~h}$ after the insult. In conclusion, the MLK inhibitor CEP-1347 has protective effects in a neonatal rat model of hypoxia-ischemia, which is mainly related to reduced apoptosis.

Copyright $\odot 2009$ S. Karger AG, Basel
\end{abstract}

\section{Introduction}

Approximately 1-2/1,000 born infants develop hypoxic-ischemic encephalopathy at term and hypoxia-ischemia (HI) is considered to be a common cause of brain injury also in preterm infants [Volpe, 2001]. Typically, HI brain injury develops with a delay during the recovery phase opening up a therapeutic window after the insult [Wyatt et al., 1989]. Hence, various neuroprotective regimens administered only after HI have proven to be efficient both according to experimental [Hagberg et al., 2006] and clinical studies [Gluckman et al., 2005]. There is considerable support for both apoptotic and immunoinflammatory mechanisms being critical for the development of neonatal HI brain injury [Silverstein et al., 1997; Cheng et al., 1998; Hagberg and Mallard, 2005; Blomgren and Hagberg, 2006]. Therefore, we are seeking a pharmacological strategy that both attenuates apoptotic cell death and modulates inflammation.

Mitogen-activated protein kinases exist in every eukaryotic cell and are also called stress activators since they react to, and are upregulated by a wide range of stimuli, including inflammatory cytokines, ischemia, growth hormones and osmotic shock. Mitogen-activated protein

Ylva Carlsson, MD

Perinatal Center, Department of Obstetrics and Gynecology

Göteborg University, Box 432

SE-405 30 Göteborg (Sweden)

Tel. +4631 78629 56, Fax +46 3178635 12, E-Mail ylva.carlsson@vgregion.se 
kinases activate the mixed lineage kinase (MLK) family, which in turn regulates c-jun N-terminal kinase (JNK). Activation of JNK leads to the phosphorylation of the transcription factor c-jun, which through cytochrome C release and induction of caspases can mediate apoptosis [Waetzig and Herdegen, 2005; Weston and Davis, 2007]. MLK has been shown to be expressed in neuronal cells and overexpression effectively induces apoptotic cell death. CEP-1347 (KT7515) is a semi-synthetic inhibitor of the MLKs. It has been shown to inhibit the activation of the MLK/JNK pathway and consequently apoptosis in neuronal cell cultures, including sensory, sympathetic and motor neurons [Maroney et al., 1999; Harris et al., 2002], as well as in an in vivo model after colchicine treatment in 7-day-old rats [Müller et al., 2006]. Furthermore, CEP-1347 also seems to modify the inflammatory response in the brain, thus downregulating a number of cytokines, for example IL- 6 and TNF- $\alpha$, thereby changing the astrocyte and microglia response to stress [Falsig et al., 2004; Lund et al., 2005]. In spite of its potential as a neuroprotectant, CEP-1347 or other MLK inhibitors have not previously been explored in neonatal models of brain injury.

The aim of the present study was to evaluate the cerebroprotective potency of CEP-1347 in a neonatal model of $\mathrm{HI}$ and to investigate its effects on apoptotic and inflammatory markers.

\section{Materials and Methods}

\section{Induction of HI in Neonatal Rats}

HI was induced in postnatal day 8 Wistar rats (Charles River, Germany) according to the Rice-Vannucci model [Rice et al., 1981] with some modifications [Andine et al., 1990]. The left carotid artery was dissected and cut between ligatures of Prolene sutures, during isoflurane anesthesia (3\% for induction and $1.5 \%$ for maintenance) in nitrous oxide/oxygen (1:1). The pups were allowed to rest for $1 \mathrm{~h}$ with their dams. They were then subjected to $7.7 \%$ oxygen in nitrogen for $55 \mathrm{~min}$. All animal experiments were approved by the Animal Ethics Committee of Göteborg.

\section{Drug Administration}

CEP-1347 was supplied by Lundbecks (Köpenhamn, Denmark). The drug [dose $1 \mathrm{mg} / \mathrm{kg}$ at a concentration of $0.2 \mathrm{mg} / \mathrm{ml}$ Solutol (10\%) in PBS] and vehicle [Solutol (10\%) in PBS] were injected subcutaneously immediately after $\mathrm{HI}, 6 \mathrm{~h}$ after $\mathrm{HI}$ and then once daily until the animals were killed. According to previous research the dose in animals for which efficacy was observed ranged from 0.1 to $3.0 \mathrm{mg} / \mathrm{kg}$, corresponding to plasma levels of 20-200 ng/ml [Waldmeier et al., 2006; Saporito et al., 2002].
Brain Injury Evaluation

Pups (CEP-1347: $\mathrm{n}=23$; vehicle: $\mathrm{n}=20$ ) were deeply anesthetized with $150 \mu$ l Pentothal ${ }^{\circledR}$ natrium $(50 \mathrm{mg} / \mathrm{ml})$ and sacrificed at 7 days after $\mathrm{HI}$ and perfused intracardially with $\mathrm{NaCl}(0.9 \%)$ followed by $5 \%$ buffered formaldehyde (Histofix; Histolab, Göteborg, Sweden). The brains were dissected out and immersionfixed in Histofix over night. After dehydration with graded ethanol and xylene, brains were paraffin-embedded and cut into 5$\mu \mathrm{m}$ coronal sections. To evaluate brain injury, sections were deparaffinized and boiled in citric acid buffer $(0.01 \mathrm{M}, \mathrm{pH} 6.0,10$ $\mathrm{min})$. Nonspecific binding was blocked for $1 \mathrm{~h}$ with $4 \%$ horse serum in PBS. Sections were incubated for $1 \mathrm{~h}$ with an MAP-2 antibody (1:2,000, Sigma), then incubated for an additional hour with biotinylated horse anti-mouse secondary antibody (1:250, Vector Laboratories, Burlingame, Calif., USA). Immunoreactivity was visualized using Vectastain ABC Elite with 3,3'-diaminobenzidine (DAB, $0.5 \mathrm{mg} / \mathrm{ml}$ ) enhanced with nickel sulfate $(15 \mathrm{mg} /$ $\mathrm{ml}$ ) [Gilland et al., 1998]. Nonspecific labeling was investigated by omitting the primary antibody.

The Olympus Micro Image analysis software system, version 4.0, was used (Olympus Optical, Tokyo, Japan) for measuring the area of tissue loss on sections stained with MAP-2. MAP-2-positive areas in the ipsilateral and in the contralateral hemisphere were outlined by an observer blinded to group belonging. Tissue loss was calculated by subtracting the MAP-2-positive area of the ipsilateral hemisphere from the contralateral hemisphere. The volume of tissue loss was calculated according to the Cavalieri principle. The formula $\mathrm{V}=\Sigma \mathrm{Apt}$ was applied, where $\mathrm{V}$ is the total volume loss expressed as $\mathrm{mm}^{3}, \Sigma \mathrm{A}$ is the sum of the areas measured, $\mathrm{p}$ is the inverse of the section's sampling fraction (in this case 100 , hence every 100th section was stained for MAP-2 and used), and $\mathrm{t}$ is the section thickness (5 $\mu \mathrm{m})$.

Brain injury in different regions (striatum, hippocampus, thalamus and cerebral cortex) was estimated using a semi-quantitative neuropathological scoring system [Bona et al., 1998; Hedtjärn et al., 2002; Hagberg et al., 2004]. The evaluation was made by an observer blinded to group belonging. Injury in the cerebral cortex was graded from 0 to $4(0=$ no observable injury; 1 = few small isolated groups of injured cells; 2 = several larger groups of injured cells; 3 = moderate confluent infarction; $4=\mathrm{ex}$ tensive confluent infarction encompassing most of the hemisphere). The damage in the hippocampus, striatum, and thalamus was assessed regarding both hypotrophy (shrinkage; $0-3$ ) and observable cell injury/infarction (0-3). Hence, the maximum score for one brain region was 6 ; scoring 0 means no damage, while 1-3 correspond to mild, moderate or severe atrophy or infarction, respectively. The total score (0-22) was the sum score for all 4 regions.

\section{Immunohistochemistry}

Pups ( $\mathrm{n}=6$ per treatment group) were deeply anesthetized with Pentothal natrium $(50 \mathrm{mg} / \mathrm{ml})$, sacrificed after $24 \mathrm{~h}$ and the brains were equilibrated in PBS containing $10 \%$ sucrose for at least $24 \mathrm{~h}$. Fresh-frozen coronal sections $(10 \mu \mathrm{m})$ were taken throughout the antero-posterior axis and used for detection of activated microglia as well as apoptosis markers.

Nonspecific binding was blocked for $30 \mathrm{~min}$ with $4 \%$ horse or goat serum (depending on the species used to raise the secondary antibody) in PBS. Primary antibodies used were: anti-apoptosisinducing factor (AIF; 1:1,000, D-20, Sc-9416, Santa Cruz, Calif., 
USA), OX-18 (1:500, MCA 51R, Serotec, Düsseldorf, Germany), OX-42 (1:50, MCA 275R, Serotec) and caspase 3 (1:50, cat. No 557035, BD Pharmingen, San Diego, Calif., USA). Primary antibodies were incubated for $60 \mathrm{~min}$ at room temperature, followed by the appropriate, biotinylated secondary antibodies for $60 \mathrm{~min}$ at room temperature. All secondary antibodies were from Vector. Visualization was performed using Vectastain ABC Elite with 0.5 $\mathrm{mg} / \mathrm{ml} \mathrm{DAB}$ enhanced with $15 \mathrm{mg} / \mathrm{ml}$ ammonium nickel sulfate, $2 \mathrm{mg} / \mathrm{ml} \beta$-D-glucose, $0.4 \mathrm{mg} / \mathrm{ml}$ ammonium chloride and 0.01 $\mathrm{mg} / \mathrm{ml} \beta$-glucose oxidase (all from Sigma). In all cases nonspecific labeling was investigated by omitting the primary antibody.

\section{Isolectin}

Sections from brains used for brain injury evaluation were also stained for isolectin $\mathrm{B}_{4}$. Sections were deparaffinized and boiled in citric acid buffer $(0.01 \mathrm{M}, \mathrm{pH} 6.0,10 \mathrm{~min})$. After washing, slides were incubated with $3 \% \mathrm{H}_{2} \mathrm{O}_{2}$ in $\mathrm{PBS}$ for 10 min. Sections were incubated for $3 \mathrm{~h}$ with isolectin $\mathrm{B}_{4}$ (Sigma), diluted 1:100, in $1 \%$ Triton X-100 in PBS. After a thorough rinse with PBS reactivity was visualized using $\mathrm{DAB}(0.5 \mathrm{mg} / \mathrm{ml})$ enhanced with nickel sulfate $(15 \mathrm{mg} / \mathrm{ml})$ [Hedtjärn et al., 2002].

\section{TUNEL}

DNA double-strand breaks were detected by a TUNEL kit. The method was performed according to the manufacturer's instructions with some modifications (Roche-Boehringer Mannheim, Mannheim, Germany). Briefly, sections were blocked with $3 \%$ bovine serum albumin in $0.1 \mathrm{M}$ Tris- $\mathrm{HCl}(\mathrm{pH} 7.5)$ for $30 \mathrm{~min}$, then incubated for 2 min on ice in $0.1 \%$ Triton X-100, $0.1 \%$ natrium citrate, followed by incubation with TUNEL reaction mixture (terminal deoxynucleotidyl transferase, fluorescein-dUTP, and deoxynucleotide triphosphate) for $60 \mathrm{~min}$ at $37^{\circ} \mathrm{C}$. After incubation with peroxidase-conjugated anti-fluorescein (diluted 1:5) at $37^{\circ} \mathrm{C}$ for $30 \mathrm{~min}$, visualization was performed using DAB $(0.5$ $\mathrm{mg} / \mathrm{ml})$ enhanced with nickel sulfate $(15 \mathrm{mg} / \mathrm{ml})$. Nonspecific labeling was investigated by omitting terminal deoxynucleotidyl transferase in the labeling procedure. There was no staining in the contralateral hemisphere.

\section{Cell Counting}

Images from brain sections with caspase 3, OX-18, OX-42, AIF, isolectin and TUNEL staining were captured by a Leica DM $6000 \mathrm{~B}$ camera and analyzed by using Stereoinvestigator 7, MicroBrightField System Inc. software. Cells in the injured hemisphere were counted in the striatum, hippocampus and cortex. The selected areas were outlined and computer-generated counting frames randomly superimposed over each region. This resulted in approximately 20 sampling sites/region/section with each counting frame being of $50 \times 50 \mu \mathrm{m}$, identical for CEP-1347- and vehicle-treated animals. In each animal, 3 slides/brain region were used for counting and the average number of positive cells/ $\mathrm{mm}^{2}$ was calculated. Results are given as mean \pm SEM for each group. The contralateral hemisphere was also examined for positive cells, but no such cells were found.

\section{Real-Time PCR}

Pups ( $n=6$ per time point per treatment) were decapitated at 4 and $8 \mathrm{~h}$ after $\mathrm{HI}$. Brain samples were homogenized by sonication in $100 \mu$ PBS buffer (pH 7.4) and total RNA was extracted accord- ing to the manufacturer's instructions, using the RNeasy Midi Kit (Qiagen GmbH, Hilden, Germany). First-strand cDNA synthesis was performed with a Superscript RNase H reverse transcriptase kit (Invitrogen, San Diego, Calif., USA), as described previously [Blomgren et al., 1999]. The following primer pairs (CyberGene $\mathrm{AB}$, Huddinge, Sweden), annealing temperatures and elongation times were used: GAPDH (NM017008): forward 5'-CTA CCC ACG GCA AGT TCA AC, reverse 5'-ACG CCA GTA GAC TCC ACG AC, $58^{\circ} \mathrm{C}, 6 \mathrm{~s}$; IL-1 $\beta$ (NM031512): forward 5'-AGC TCC ACG GGC AAG ACA TAG G, reverse 5'-GGA TTG CTT CCA AGC CCT TGA C, $59^{\circ} \mathrm{C}, 6 \mathrm{~s}$; IL-6 (NM012589): forward 5'-CCC AAC TTC CAA TGC TCT CCT AAT G, reverse 5'-GCA CAC TAG GTT TGC CGA GTA GAC C, $63^{\circ} \mathrm{C}, 6$ s; MCP-1 (AF058786): forward 5'-TCA CGC TTC TGG GCC TGT TG, reverse 5'-CAG CCG ACT CAT TGG GAT CAT C, $58^{\circ} \mathrm{C}, 5 \mathrm{~s}$. For quantification and for estimating amplification efficiency, a standard curve for each gene product was generated using increasing concentration of cDNA. The amplification transcripts were quantified with the relative standard curve and normalized against GAPDH.

\section{ELISA}

The brain homogenates, prepared from the same samples as for RT-PCR, were centrifuged at $10,000 \mathrm{~g}$ at $4^{\circ} \mathrm{C}$ for $15 \mathrm{~min}$. The supernatants were collected and protein concentration measured by the UV method presented by Whitaker and Granum [1980] adapted for microplates, and used for the ELISAs. For the assays, a rat IL-1 $\beta$ ELISA kit (Quantikine M RLB00, R\&D Systems) and a rat IL-6 ELISA kit (KRC0062, Biosource) were used and performed as recommended by the manufacturers.

\section{Immunoblotting}

Pups ( $\mathrm{n}=6$ per time point per treatment) were decapitated at 4 and $8 \mathrm{~h}$ after HI. Homogenate samples were used. Immunoblotting was performed as previously described [Wang et al., 2003]. The primary antibodies used were: $\mathrm{p}-J N K$ (1:1,000, No. 9251, Cell Signaling Technology, Stockholm, Sweden) and p-c-jun (Ser73, 1: 1,000, No. 9164, Cell Signaling Technology). After washing, membranes were incubated with the appropriate peroxidase-conjugated secondary antibodies (Vector Laboratories). Immunoreactive species were visualized using SuperSignal West Dura chemiluminescence substrates (Pierce, Rockford, Ill., USA) and a cooled CCD camera (LAS1000; Fujifilm, Tokyo, Japan). Immunoreactive bands were quantified using Image Gauge software (version 3.3; Fujifilm).

\section{Statistics}

The nonparametric Mann-Whitney U test was used to compare brain injury and positive cell counting results in CEP-1347treated versus vehicle-treated animals. Regarding the mechanistic part of the study our aim was to detect a 2 -fold difference (power $80 \%, \mathrm{p}<0.05$ ) between groups and based on the standard deviation in our previous studies it was calculated that we needed 6 animals/group. Differences with a p value $<0.05$ were considered statistically significant. Values are expressed as means \pm SEM. 

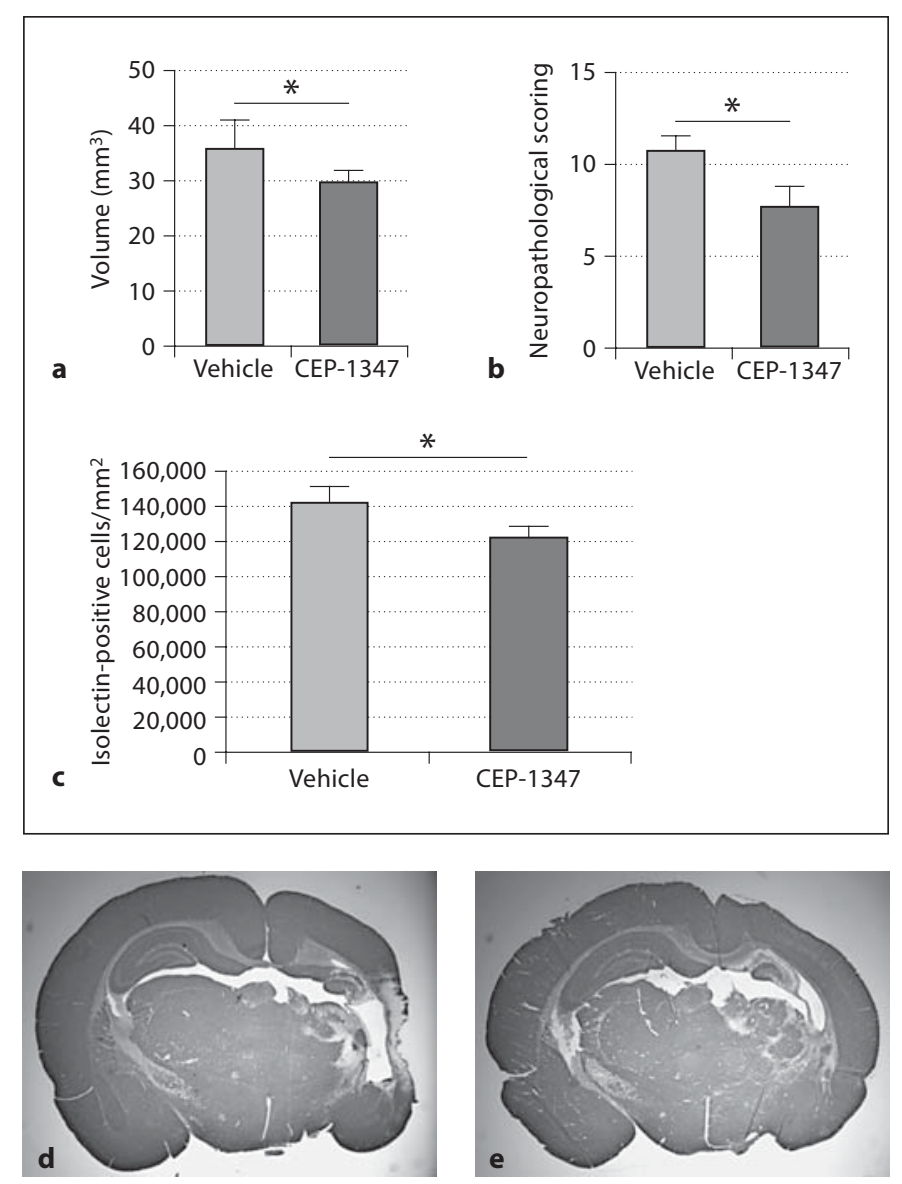

Fig. 1. Brain injury evaluation. Brain injury in the CEP-1347 and vehicle groups. The total tissue volume loss (a) and neuropathology score (b) were reduced in the CEP-1347-treated group versus control. CEP-1347 also reduced isolectin staining as compared to vehicle ( $p=0.038 ; c)$. Photomicrographs of sections after MAP-2 immunohistochemical staining 7 days after $\mathrm{HI}$, demonstrating a reduction in cerebrocortical, thalamic and hippocampal injury in the CEP-1347 group (e) compared with vehicle controls (d). Data were analyzed with the Mann-Whitney $U$ test and values expressed as means $\pm \mathrm{SEM} ;{ }^{*} \mathrm{p} \leq 0.05$.

\section{Results}

\section{CEP-1347 Protects against HI Brain Damage}

Brain infarction and/or selective neuronal injury were observed in the cerebral cortex, hippocampus, striatum and thalamus ipsilateral to the carotid artery occlusion at 7 days after HI (fig. 1d, e). There was a $28 \%$ decrease in overall tissue volume loss $(\mathrm{p}=0.019)$ in CEP-1347-treated as compared to vehicle-treated animals (fig. 1a). Neu-

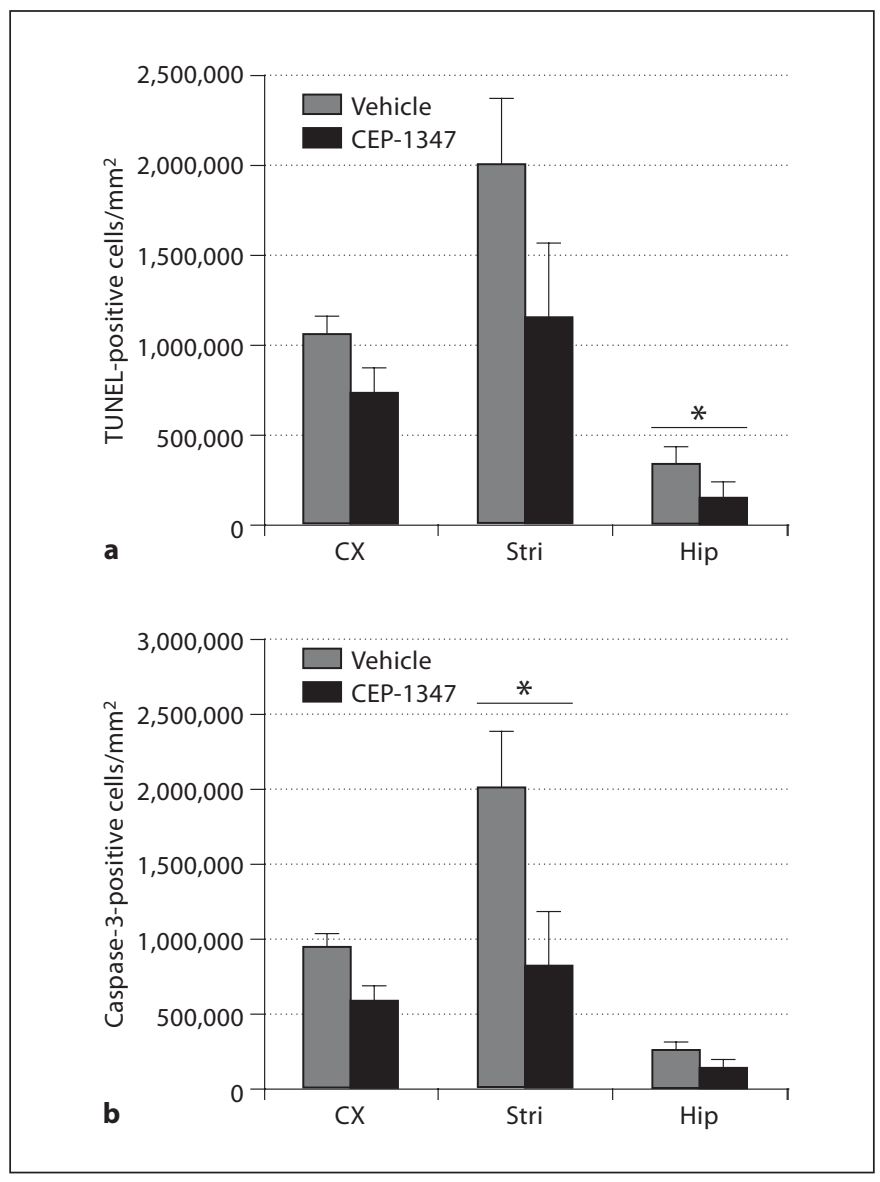

Fig. 2. CEP-1347 reduces apoptosis. Caspase 3 immunoreactivity and DNA double-strand breaks detected with TUNEL were reduced in CEP-1347- as compared to vehicle-treated rats. a TUNEL staining revealed significantly $(\mathrm{p}=0.021)$ decreased levels of DNA injury in the hippocampus, with a similar trend in the striatum and in the cortex $(\mathrm{p}=0.066)$, at $24 \mathrm{~h}$ after HI in CEP-1347treated compared to vehicle-treated animals. b There was a significant $(\mathrm{p}=0.047)$ reduction of cells expressing the cleaved activated form of caspase 3 in the striatum $24 \mathrm{~h}$ after HI, with a similar trend in the hippocampus $(\mathrm{p}=0.07)$ and in the cortex $(\mathrm{p}=0.08)$. CX = Cortex; Stri $=$ striatum; Hip = hippocampus. Differences were analyzed with the Mann-Whitney $U$ test and expressed as means $\pm \mathrm{SEM} ;{ }^{*} \mathrm{p} \leq 0.05$.

roprotection by CEP-1347 was also evident when injury was assessed by neuropathological scoring ( $\mathrm{p}=0.046$; fig. 1b).

The number of isolectin-positive cells with the morphology of activated microglia, i.e. retracted processes and rounded cell body phenotype, was counted, which was substantially increased after HI. CEP-1347 reduced the number of isolectin-positive cells, at 7 days after $\mathrm{HI}$, compared to vehicle-treated animals $(p=0.038$; fig. $1 c)$. 
Table 1. Immunohistochemistry after $\mathrm{HI}$ in the vehicle and CEP1347 group

$\begin{array}{lr}\text { OX-42-positive cells } / \mathrm{mm}^{2} & \\ \text { Vehicle } & 584,278 \pm 171,973 \\ \text { CEP-1347 } & 779,639 \pm 224,145 \\ \text { OX-18-positive cells } / \mathrm{mm}^{2} & \\ \text { Vehicle } & 3,911,917 \pm 180,024 \\ \text { CEP-1347 } & 4,688,889 \pm 689,289\end{array}$

Expression of OX-42 (CR3) and OX-18 (MHC I) immunoreactivity in CEP-1347-treated versus vehicle-treated animals $24 \mathrm{~h}$ after HI.

Table 2. IL-6, IL-1 $\beta$ and MCP-1 mRNA after HI in the vehicle and CEP-1347 group

\begin{tabular}{lll}
\hline & $4 \mathrm{~h}$ & $8 \mathrm{~h}$ \\
\hline IL-6 & & \\
$\quad$ Vehicle & $0.127 \pm 0.016$ & $0.198 \pm 0.018$ \\
CEP-1347 & $0.100 \pm 0.013$ & $0.378 \pm 0.159$ \\
IL-1 $\beta$ & & \\
$\quad$ Vehicle & $0.648 \pm 0.100$ & $0.562 \pm 0.065$ \\
$\quad$ CEP-1347 & $0.527 \pm 0.060$ & $0.662 \pm 0.0834$ \\
MCP-1 & $0.412 \pm 0.049$ & $0.278 \pm 0.045$ \\
$\quad$ Vehicle & $0.323 \pm 0.033$ & $0.384 \pm 0.133$ \\
CEP-1347 &
\end{tabular}

Cytokine mRNA levels are expressed/GAPDH and given as means \pm SEM.

We also analyzed data according to gender, but no differences were detected [Zhu et al., 2006].

\section{CEP-1347 Reduces Apoptosis}

TUNEL staining was significantly $(\mathrm{p}=0.021)$ decreased in the hippocampus $24 \mathrm{~h}$ after HI in CEP-1347treated animals (fig. 2a) and a similar tendency was found in the cerebral cortex and striatum $(\mathrm{p}=0.066)$. This is consistent with a significant $(\mathrm{p}=0.047)$ reduction of cells expressing the cleaved activated form of caspase 3 in the striatum $24 \mathrm{~h}$ after $\mathrm{HI}$ (fig. $2 \mathrm{~b}$ ) and a similar tendency is found in the cortex and hippocampus. There was no significant difference in the number of apoptosis-inducing factor (AIF)-positive cells between CEP-1347-treated and vehicle-treated animals (data not shown).

Total p-JNK immunoreactivity was significantly decreased at $4 \mathrm{~h}$ (CEP-1347 $53.31 \pm 16.30$ vs. vehicle 58.08 $\pm 40.80 \mathrm{OD} / \mu \mathrm{g}$ total protein, $\mathrm{p}=0.049$ ), but no statisti-
Table 3. IL- 6 and IL-1 $\beta$ protein levels $8 \mathrm{~h}$ after $\mathrm{HI}$ in the vehicle and CEP-1347 group

$\begin{array}{ll}\text { IL-6 } & \\ \text { Vehicle } & 116.65 \pm 12.60 \\ \text { CEP-1347 } & 135.59 \pm 6.33 \\ \text { IL-1 } \beta & \\ \text { Vehicle } & 41.50 \pm 6.51 \\ \text { CEP-1347 } & 51.17 \pm 13.04\end{array}$

Protein concentrations are expressed as $\mathrm{pg} / \mathrm{mg}$ and given as mean \pm SEM

cally significant difference was detected $8 \mathrm{~h}$ after $\mathrm{HI}(\mathrm{p}=$ 0.404 ). There was no significant change in c-jun levels after HI in CEP-treated animals compared to controls (data not shown).

\section{CEP-1347 Effect on Inflammation}

There was no significant difference in the expression of OX-42 (CR3) and OX-18 (MHC I) immunoreactivity in CEP-1347-treated versus vehicle-treated animals at $24 \mathrm{~h}$ after HI (table 1). The expression of mRNA for the pro-inflammatory cytokines IL-1 $\beta$, IL- 6 and MCP- 1 was not different in CEP-1347-treated versus vehicle-treated animals at 4 and $8 \mathrm{~h}$ after $\mathrm{HI}$ (table 2). Similarly, protein expression of IL-1 $\beta$ and IL- 6 was not different in CEP1347-treated versus vehicle-treated animals at $8 \mathrm{~h}$ after HI (table 3).

\section{Discussion}

This report demonstrates that the MLK inhibitor CEP1347 reduces brain injury to a moderate degree in a neonatal HI model in rats. To our knowledge, this is the first report showing involvement of MLKs in neonatal brain injury. There was overall protection according to evaluation of tissue volume loss and neuropathological scoring. The reduction in brain injury was accompanied by a marked reduction of microgliosis at 7 days offering additional indirect support of the cerebroprotective efficacy of CEP-1347 in this model. Our results agree with previous reports that CEP-1347 exhibits neuroprotective effects both in vitro and in vivo. Death by withdrawal of nerve growth factor, exposure to ultraviolet irradiation, or exposure to oxidative stress in cultured rat sympathetic neurons and neuronally differentiated PC12 cells were prevented by CEP-1347 [Maroney et al., 1999]. CEP-1347 
has also been shown to promote motor neuron survival in cultured rat embryonic motoneurons [Maroney et al., 1998] as well as having an effect on the survival of embryonic rat dopaminergic neurons in culture, or after transplantation into the striatum in hemiparkinsonian rats [Boll et al., 2004].

The present results suggest that CEP-1347 attenuates caspase-dependent cell death after neonatal $\mathrm{HI}$ and the decrease of the apoptotic marker TUNEL further supports CEP-1347 being anti-apoptotic. This agrees with previous studies demonstrating that CEP-1347 promotes neuronal survival in vitro and that CEP-1347 inhibits neuronal apoptotic cell death caused by nerve growth factor withdrawal [Harris et al., 2002].

It has been suggested that MLK inhibition attenuates JNK activation and phosphorylation of c-jun [Wang et al., 2004]. Indeed, c-jun is activated after HI [Gilby et al., 1997] and JNK3 gene ablation is associated with decreased brain damage and caspase 3 activation after neonatal HI [Pirianov et al., 2007]. The decrease in p-JNK expression in our study was marginal $(\mathrm{p}=0.049)$ and no significant drop in c-jun expression was detected. This is in agreement with previous studies where CEP-1347 has been shown to inhibit JNK1, p-c-jun increase and apoptosis both in vitro and in vivo [Maroney et al., 1998; Lund et al., 2005; Müller et al., 2006]. The lack of effect of CEP1347 on c-jun in the present study could be a result of the fact that whole-brain tissue analysis was performed, which may not detect regional differences. Furthermore, JNK activation could be quite transient and therefore difficult to detect [Pirianov et al., 2007] unless tissue is sampled with very high time resolution, which was not done presently. Additional detailed studies are required to determine how the MLK-JNK pathway is specifically affected in the immature brain after HI.

In our study, there was no significant difference in AIF-expressing cells between CEP-1347-treated and vehicle-treated rats. This is consistent with a study by Bogoyevitch et al. [2004] where CEP-1347 seemed to interact with the apoptotic pathway involving caspase 3 and JNK, but not AIF.

$\mathrm{HI}$ is accompanied by a marked activation of microglia and expression of pro-inflammatory cytokines [Bona et al., 1999] and at least some components of the immune system appear to be involved in brain injury [Silverstein et al., 1997; Hagberg et al., 2006]. To explore whether CEP-1347 modifies the acute microglia response in the early phase of injury progression, we investigated the expression of OX-18 (MHC I antigen) and OX-42 (CR3) on microglia at $24 \mathrm{~h}$. According to McRae et al. [1995], the expression of OX-18 (MHC I antigen) and OX-42 (CR3) on microglia occurs early and these are sensitive markers of microglial activation after HI. In our study, neither the number of microglia-expressing CR3 and MHC I antigens nor the cytokine response (IL-1 $\beta$, IL- 6 and MCP-1) were consistently affected. These results suggest that CEP-1347 does not exert a strong anti-inflammatory effect after HI in this model. It is important to point out, however, that due to high variability and the limited number of animals ( $n=6 /$ group) we only had statistical power $(80 \%)$ to detect 1.5 - to 3 -fold differences between groups for the various inflammatory markers. These results agree with CEP-1347 having mixed effects on cytokine (MCP-1, IL-1 $\beta$ and IL-6) expression also in human and murine microglial cultures stimulated by lipopolysaccharide [Lund et al., 2005].

In summary, this report implicates that post-HI treatment with CEP-1347, an MLK inhibitor, attenuates injury and decreases caspase-dependent cell death, but does not seem to have a major effect on the inflammatory response in a neonatal rat model of HI. The drug may have potential as a clinical neuroprotective treatment in neonates as it is well tolerated in humans [Parkinson Study Group, 2004 and 2007], but its mechanisms of action remain to be explored further.

\section{Acknowledgements}

We are very grateful to Lundbeck, Köpenhamn for supplying us with CEP-1347. This work was supported by Swedish governmental grants to researchers in the public health service (ALFGBG2863) (H.H.), The Swedish Medical Research Council (VR 2006-3396) (H.H.), as well as MRC strategic award (UK, P19381) (H.H.), Martina and Wilhelm Lundbergs fund (Y.C.), SU foundations (Y.C.) and funds from the Göteborg Medical Society (Y.C.).

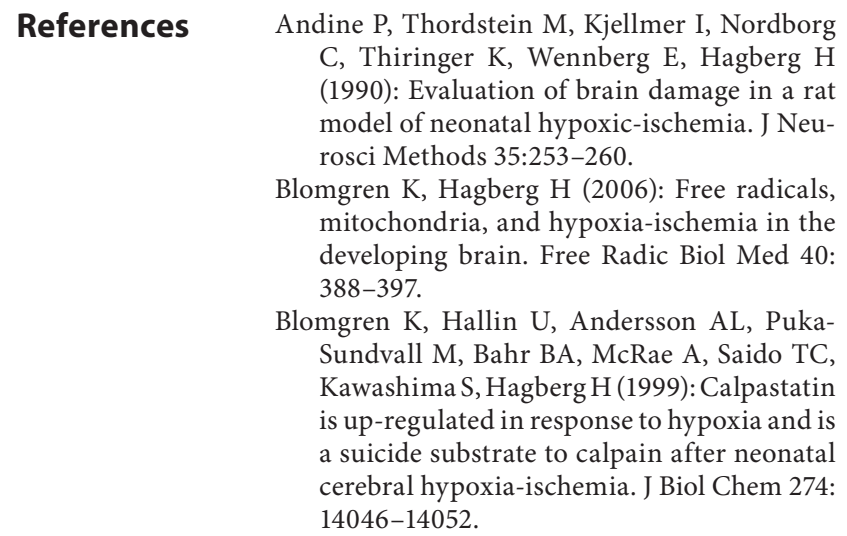

Dev Neurosci 2009;31:420-426 425 
Bogoyevitch MA, Boehm I, Oakley A, Ketterman AJ, Barr RK (2004): Targeting the JNK MAPK cascade for inhibition: basic science and therapeutic potential. Biochim Biophys Acta 1697:89-101.

Boll JB, Geist MA, Kaminski Schierle GS, Petersen K, Leist M, Vaudano E (2004): Improvement of embryonic dopaminergic neurone survival in culture and after grafting into the striatum of hemiparkinsonian rats by CEP1347. J Neurochem 88:698-707.

Bona E, Andersson AL, Blomgren K, Gilland E, Puka-Sundvall M, Gustafson K, Hagberg H (1999): Chemokine and inflammatory cell response to hypoxia-ischemia in immature rats. Pediatr Res 45:500-509.

Dona E, Hagberg H, Loberg EM, Bagenholm R, Thoresen M (1998): Protective effects of moderate hypothermia after neonatal hypoxia-ischemia: short- and long-term outcome. Pediatr Res 43:738-745.

Cheng Y, Deshmukh M, D’Costa A, Demaro JA, Gidday JM, Shah A, Sun Y, Jacquin MF, Johnson EM, Holtzman DM (1998): Caspase inhibitor affords neuroprotection with delayed administration in a rat model of neonatal hypoxic-ischemic brain injury. J Clin Invest 101:1992-1999.

-Falsig J, Porzgen P, Lotharius J, Leist M (2004): Specific modulation of astrocyte inflammation by inhibition of mixed lineage kinases with CEP-1347. J Immunol 173:2762-2770.

- Gilby KL, Armstrong JN, Currie RW, Robertson HA (1997): The effects of hypoxia-ischemia on expression of c-Fos, c-Jun and Hsp70 in the young rat hippocampus. Brain Res Mol Brain Res 48:87-96.

-Gilland E, Bona E, Hagberg H (1998): Temporal changes of regional glucose use, blood flow, and microtubule-associated protein 2 immunostaining after hypoxia-ischemia in the immature rat brain. J Cereb Blood Flow Metab 18:222-228.

-Gluckman PD, Wyatt JS, Azzopardi D, Ballard R, Edwards AD, Ferriero DM, Polin RA, Robertson CM, Thoresen M, Whitelaw A, Gunn AJ (2005): Selective head cooling with mild systemic hypothermia after neonatal encephalopathy: multicentre randomised trial. Lancet 365:663-670.

-Hagberg H, Mallard C (2005): Effect of inflammation on central nervous system development and vulnerability. Curr Opin Neurol 18:117-123.

-Hagberg H, Rousset CI, Wang X, Mallard C (2006): Mechanisms of perinatal brain damage and protective possibilities. Drug Discov Today Dis Mech 3:397-407.
Hagberg H, Wilson MA, Matsushita H, Zhu C, Lange M, Gustavsson M, Poitras MF, Dawson TM, Dawson VL, Northington F, Johnston MV (2004): Parp-1 gene disruption in mice preferentially protects males from perinatal brain injury. J Neurochem 90:10681075.

Harris CA, Deshmukh M, Tsui-Pierchala B, Maroney AC, Johnson EM Jr (2002): Inhibition of the c-Jun N-terminal kinase signaling pathway by the mixed lineage kinase inhibitor CEP-1347 (KT7515) preserves metabolism and growth of trophic factor-deprived neurons. J Neurosci 22:103-113.

Hedtjärn M, Leverin AL, Eriksson K, Blomgren K, Mallard C, Hagberg H (2002): Interleukin-18 involvement in hypoxic-ischemic brain injury. J Neurosci 22:5910-5919.

Lund S, Porzgen P, Mortensen AL, Hasseldam H, Bozyczko-Coyne D, Morath S, Hartung T, Bianchi M, Ghezzi P, Bsibsi M, Dijkstra S, Leist M (2005): Inhibition of microglial inflammation by the MLK inhibitor CEP-1347. J Neurochem 92:1439-1451.

Maroney AC, Finn JP, Bozyczko-Coyne D, O'Kane TM, Neff NT, Tolkovsky AM, Park DS, Yan CY, Troy CM, Greene LA (1999): CEP-1347 (KT7515), an inhibitor of JNK activation, rescues sympathetic neurons and neuronally differentiated PC12 cells from death evoked by three distinct insults. J Neurochem 73:1901-1912.

Maroney AC, Glicksman MA, Basma AN, Walton KM, Knight E Jr, Murphy CA, Bartlett BA, Finn JP, Angeles T, Matsuda Y, Neff NT, Dionne CA (1998): Motoneuron apoptosis is blocked by CEP-1347 (KT 7515), a novel inhibitor of the JNK signaling pathway. J Neurosci 18:104-111.

McRae A, Gilland E, Bona E, Hagberg H (1995): Microglia activation after neonatal hypoxicischemia. Brain Res Dev Brain Res 84:245252.

Müller GJ, Geist MA, Veng LM, Willesen MG Johansen FF, Leist M, Vaudano E (2006): A role for mixed lineage kinases in granule cell apoptosis induced by cytoskeletal disruption. J Neurochem 96:1242-1252.

Parkinson Study Group PSG (2004): The safety and tolerability of a mixed lineage kinase inhibitor (CEP-1347) in PD. Neurology 62: 330-332.

Parkinson Study Group PRECEPT Investigators (2007): Mixed lineage kinase inhibitor CEP1347 fails to delay disability in early Parkinson disease. Neurology 69:1480-1490.
Pirianov G, Brywe KG, Mallard C, Edwards AD, Flavell RA, Hagberg H, Mehmet H (2007): Deletion of the c-Jun N-terminal kinase 3 gene protects neonatal mice against cerebral hypoxic-ischaemic injury. J Cereb Blood Flow Metab 27:1022-1032.

Rice JE 3rd, Vannucci RC, Brierley JB (1981): The influence of immaturity on hypoxic-ischemic brain damage in the rat. Ann Neurol 9: 131-141.

Saporito MS, Hudkins RL, Maroney AC (2002): Discovery of CEP-1347/KT-7515, an inhibitor of the JNK/SAPK pathway for the treatment of neurodegenerative diseases. Prog Med Chem 40:23-62.

- Silverstein FS, Barks JD, Hagan P, Liu XH, Ivacko J, Szaflarski J (1997): Cytokines and perinatal brain injury. Neurochem Int 30:375383.

Volpe JJ (2001): Neurology of the Newborn, ed 4. Philadelphia, WB Saunders.

Waetzig V, Herdegen T (2005): Context-specific inhibition of JNKs: overcoming the dilemma of protection and damage. Trends Pharmacol Sci 26:455-461.

Waldmeier P, Bozyczko-Coyne D, Williams M, Vaught JL (2006): Recent clinical failures in Parkinson's disease with apoptosis inhibitors underline the need for a paradigm shift in drug discovery for neurodegenerative diseases. Biochem Pharmacol 72:1197-1206.

-Wang LH, Besirli CG, Johnson EM Jr (2004): Mixed-lineage kinases: a target for the prevention of neurodegeneration. Annu Rev Pharmacol Toxicol 44:451-474.

-Wang X, Zhu C, Qiu L, Hagberg H, Sandberg M, Blomgren K (2003): Activation of ERK1/2 after neonatal rat cerebral hypoxia-ischaemia. J Neurochem 86:351-362.

Weston CR, Davis RJ (2007): The JNK signal transduction pathway. Curr Opin Cell Biol 19:142-149.

Whitaker JR, Granum PE (1980): An absolute method for protein determination based on difference in absorbance at 235 and $280 \mathrm{~nm}$. Anal Biochem 109:156-159.

Wyatt JS, Edwards AD, Azzopardi D, Reynolds EO (1989): Magnetic resonance and near infrared spectroscopy for investigation of perinatal hypoxic-ischaemic brain injury. Arch Dis Child 64:953-963.

Zhu C, Xu F, Wang X, Shibata M, Uchiyama Y, Blomgren K, Hagberg H (2006): Different apoptotic mechanisms are activated in male and female brains after neonatal hypoxiaischaemia. J Neurochem 96:1016-1027. 